I.a muerte sin llanto: violencia y vida cotidiana en Brasil.

\section{NANCY SCHEPER-HugheS}

Editorial Ariel, Barcelona, 1997

569 páginas, incluye ilustraciones
GANADOR DE TRES PREMIOS IMPORTANTES Y NOMINADO A OTROS DESDE SU publicación en inglés en 1992, este libro es indispensable para quienes estén interesados en el estudio de la desnutrición, la salud materna y el maltrato infantil desde la perspectiva de la antropología médica, y se recomienda como un texto de lectura obligatoria para los antropólogos.

En La muerte sin llanto, la autora presenta un análisis descarnado de la pobreza, las historias reproductivas de la mujer y las tristes y cortas vidas de los bebés de una zona del nordeste de Brasil, en el estado de Pernambuco, llamada, ficticiamente, Alto do Cruzeiro, pero que puede ser cualquier otro sitio de latinoamérica. El topónimo usado es bastante apropiado, pues significa Loma de la crucifixión, lugar en donde el perfume de la caña de azúcar y los ingenios situados en las plantaciones, que funcionan desde la época de la esclavitud, se mezclan con el vaho infecto de las aguas envenenadas e inmundas que la gente tiene que beber y usar para lavar la ropa.

El nordeste de Brasil ha sido cruelmente flagelado por la sequía, la hambruna, la violencia y el desplazamiento de sus gentes. El sufrimiento diario que tienen que soportar los habitantes de esta zona, en su mayoría descendientes de esclavos, por causa del abandono social a que están expuestos, se complica con la presencia de escuadrones de la muerte. Desafortunadamente, muchos de los que logran sobrevivir a la mortalidad infantil, a la locura producida por el delirio del hambre y a muchas otras enfermedades endémicas caen más tarde, víctimas del terror y las atrocidades cometidas por los grupos paramilitares.

La elegancia de la prosa de esta etnografía, que se lee a veces como una novela, termina por realzar el drama y el horror de la muerte diaria, siempre presente en los cuerpos martirizados de los infantes sentenciados a morir de hambre que viven en este Gólgota. Se calcula que durante la dictadura militar casi la mitad de los niños nacidos en esta zona moría antes de los cinco años. También se encontró que, en promedio, las mujeres entrevistadas habían tenido alrededor de nueve embarazos y tenían cuatro hijos sobrevivientes. El resto de embarazos había terminado en abortos espontáneos, bebés nacidos muertos o que morían inmediatamente después, o antes de un año.

La tesis principal del libro es la relación entre el amor maternal y la mortalidad infantil, analizando la cultura y las carencias materiales y emocionales y sus efectos en las decisiones morales y prácticas con respecto a la crianza de los hijos. En realidad, después de leer este libro ya no sabemos a ciencia cierta qué significa amor materno, pues en este caso se manifiesta muchas veces de una manera brutal.

Lo que más impresiona a la autora, y que justifica, en parte, su controvertida teoría de la selección benigna, es decir que las madres seleccionan cuáles de sus bebés sobreviven y cuáles no -una afirmación extremadamente dura, que podrá parecer crueles el hecho de que éstas no expresan los sentimientos apropiados cuando mueren sus bebés. No hay llanto ni festejos o celebraciones rituales, como los alabaos del Pacífico colombiano, pero sí indiferencia, notándose la falta de afecto entre la madre y sus bebés. Los infantes anónimos son enterrados rápidamente en cajones de cartón, sin ninguna ceremonia. Si la muerte diaria no fuera tratada de manera sumaria podemos imaginar el desgaste emocional y el costo de las celebraciones rituales, en especial en esta comunidad tan maltratada.

Estas afirmaciones con respecto a la indiferencia pueden ser muy cuestionables, en la medida en que la expresión de emociones frente a la muerte varía mucho. El llanto no es la única expresión de duelo ni ocurre en todas las culturas. Por otro lado, muchas culturas tienen la tradición de contratar mujeres para lamentar y llorar los muertos ajenos. También hay variaciones por género; no se espera que los hombre lloren y menos por la muerte de un bebé recién nacido. Sería interesante comparar las expresiones de duelo cuando ocurre algún caso de mortalidad infantil en la clase media o alta, en la cual las encrucijadas morales descritas por la autora son diferentes. Bien sabemos que en épocas pasadas la muerte de 
los bebés era una ocurrencia normal en todos los grupos sociales, debido a las condiciones generales de la salud. En este trabajo falta una comparación de los índices de mortalidad en todo Brasil, y de los comportamientos frente a la muerte a lo largo del siglo, en lo posible dividida por clase social o, por lo menos, por ocupación o nivel de escolaridad.

La historia del libro comienza en 1964, cuando la autora trabajaba como voluntaria de los cuerpos de paz en el área de salud comunitaria. Este origen, autodefinido como estigmatizante, muy cerca de ser una misionera cristiana, presenta algunos conflictos éticos y metodológicos para la autora, en cuanto a su responsabilidad como antropóloga, crítica de un sistema político y económico muy desigual, o como compañera de lucha de las mujeres de la comunidad. Scheper-Hughes salió del Alto do Cruzeiro a obtener su doctorado en antropología y para ello hizo trabajo de campo con campesinos irlandeses, donde ni el sitio ni la cultura ni la gente tenían nada que ver con Brasil. En la década de 1980, un colega brasileño la convenció de que regresara a Brasil y ella lo hizo, acompañada de su esposo y de sus hijos. Entre 1982 y 1989 regresó varias veces para realizar, por último, catorce meses de trabajo de campo.

Por más que la autora haya hecho un esfuerzo para criticar su experiencia personal y alejarse de su pasado con los cuerpos de paz, su trayectoria cuasi religiosa se refleja en sus perspectivas sobre lo que debería ser la manera ideal de manejar la reproducción femenina y, en general, sobre las políticas internacionales de control de la población y acceso al aborto; es decir, sus propios valores estadounidenses de clase media aparecen como una sombra. Como una manera de exorcizar esa etapa de su vida, siente la necesidad de escribir y comparar su experiencia personal y narra, con lujo de detalles, la participación de sus hijos y esposo en el trabajo de campo y cómo éste los afectó. Poco ha cambiado en la zona desde los años I960; más bien, las cosas han empeorado para los residentes del Alto do Cruzeiro, mientras que Nancy y su familia regresaron a su vida cómoda en California.

De cualquier manera, este libro nos afecta profundamente, no sólo por las narrativas tan sobrecogedoras, sino porque vemos a diario el hambre, el maltrato y el abandono infantil a nuestro alrededor. Con llanto o sin llanto, estas muertes infantiles son el desperdicio de la vida humana y el desgaste de la salud de la mujer, y es necesario hacer algo al respecto.

Patricia Tovar Investigadora del Instituto Colombiano de Antropología e Historia 